\title{
Changing Femininities, Changing Masculinities Social Change, Gender Identities and Sexual Orientations
}

\author{
by Elisabetta Ruspini \\ University of Milano-Bicocca, Italy \\ Sociological Research Online, Volume 12, Issue 1, \\ < http://umw. socresonline.org.uk/12/1/ruspini.htm/> \\ doi:10.5153/sro. 1515
}

Received: 30 Jan 2007 Accepted: 30 Jan 2007 Published: 31 Jan 2007

Introduction

1.1 The aim of this special section of Sociological Research Online launches is to explore, both theoretically and substantively, the issues that surround notions of social change, gender identities and sexual orientations.

1.2 The social issues associated with changing gender identities and the shift between "old" and "new" models of femininity and masculinity challenges the two-gender system. Homosexuality, bisexuality and trans-sexuality show how greatly the processes of identity construction have changed in present-day societies and how different they are in these processes, compared with those of modern or traditional societies.

1.3 However, these issues are often neglected by existing social agendas, including policies on gender equality and social exclusion. Social institutions are often intolerant of gender diversity. Many areas of social and economic life, for example the right to motherhood-fatherhood, need to be reviewed to ensure full citizens' rights for non heterosexual people, and to reduce the power of heteronormativity. In many European countries heterosexuality and marriage have long been protected by law and still give access to various rights under social security. Also, there has been a general lack of attention (and a lack of comparative research) to the complex intersection between forms of social disadvantage such as gender and sexual orientation.

1.4 These obstacles have profound impacts on homosexual, bisexual, transgender and transsexual people's lives. Whilst their experiences are very diverse, they share the experience of living in a society where gender diversity is not fully tolerated, and where social institutions act to perpetuate the erasure of gender fluidity.

\section{The silence}

2.1 Gender is one of the most interesting dimensions of social change; but it is also more controversial and less investigated in many European contexts. A blanket of silence continues to shroud thinking on the transformations of gender identities and on the effects caused by these changes on the relationships between men and women, their forms of co-habitation, and experiences of fatherhood and motherhood.

2.2 The silence becomes palpable if we think that, generally speaking, the issue of the relation between sex and gender identity is not posed, because it is thought that there is no conflict between the latter and personal autonomy: boys will "naturally" become men, and girls women ("Biology is destiny: a boy will be a man; a girl will become a woman"). Moreover, gender identity is a stable characteristic, which will not encounter changes in time: the relationship between sexual characteristics and gender has historically developed within a schema considered as natural, permanent and compulsory, according to consolidated models and pre-defined life destinies (Scott, 1999). In other words, belonging to a sex has constituted the primary, basic datum of self-perception.

2.3 Men and women are also perceived as complementary, i.e. biologically destined to an eternal relation of attraction ("What is a woman without a man?"; "And a man without a woman?"; "Women and men reciprocally complete each other"; "Men are naturally attracted by women; women are naturally attracted by men"). Furthermore, bodily features are synonymous with differences in skills and aptitudes: hence the idea of the "naturalness" of a system of gender relations marked by an unequal distribution of material and symbolic resources. And so we have women "good at" caring work, and "rational", "dynamic" and "stronger" men who successfully devote themselves to production activities and supporting their families. The social construction of fatherhood and motherhood is also outlined, sustained and strengthened by many commonplaces: "fathers are not very suited to caring activities"; "children must stay with their 
mother"; "women are made to be wives and mothers"; "women are fulfilled when they become mothers, men in supporting their family".

2.4 This rigid conception of the man-woman relation is expressed through a delimiting of ways of being, characters, behaviours, as well as roles. This has created an often very burdensome constraint, for both sexes: a constraint which is socially guaranteed and controlled, even in the substantial long-term geographic and historical variants in which it appears. This dichotomy - historically constructed around male and female biological features - also ensured the conditions for the development and survival of industrial society, characterised by standardised life courses and families with a single, stable wage-earner, where the salary of the male head of the family was assimilated to a family wage. Talcott Parsons (Parsons, 1954) clearly theorised the separation of roles between women and men and the differentiation of the sexual roles in the family. Mother and father are representatives and bearers, for their children, of two distinct, complementary codes: the husband-father is the instrumental leader, assigned with the management of social relations and the financial support of the family and its members; he is the figure which indicates limits and duties, who exercises authority, who favours the interiorisation of the rules of social living. The wife-mother instead has the role of expressive leadership centred on internal relations within the family and its affective function: she is the parent with the task of ensuring the immediate satisfaction of children's needs, tending to yield to their demands. For structural-functionalists, the biological-sexual difference essentially corresponds to a difference in aptitude which reserves different specific scopes to men and women, functional to the maintenance of order and equilibrium in society. And the family is interpreted as a functional necessity, because without it the human species would die out.

2.5 The blanket of silence becomes thicker if attention is focussed on the plurality of sexual attitudes - i.e. the affective and erotic attraction which may be directed towards men, women or both sexes - and on the discriminations linked to the lack of recognition of this plurality, which is still incompatible with the language of inclusion in rights of citizenship. If "natural" relations between women and men are defined as "normal and legitimate", the "natural basis of society", non-heterosexual relations continue to be an embarrassing, thorny, unexpected and even threatening subject: men who desire and love men, women who desire and love women, people attracted by both women and men, men and women who have changed their sexual characters and who desire to construct an affective life as a couple.

2.6 The false indifference towards homosexuality and bisexuality, seen in stereotypes, negative attitudes and commonplaces which consider love and sexual desire between persons of the same sex as perversions ("Gays and lesbians are against nature; they are unable to have lasting relationships; they represent sexual excess; they can't take care of children; they are a threat for 'real families': homosexuality and bisexuality represent a confusion between the sexes") produce the effect of making these attitudes invisible in everyday life. In order to avoid sanctions, many gays, lesbians and bi-sexual people strive to behave according to hetero-normative expectations. In other words, they seek to behave like heterosexuals to mask a behaviour seen as "deviant" and thus to prevent results which could compromise their working situation and career prospects; social relations; family relations (see the papers by Shipman and Smart; Reynolds). For example, "coming out" in one's family may be a very difficult and painful process, due to the fear of breaking up the relationship and thus losing affective support. Visibility is considered particularly "dangerous", and therefore unpleasant, for certain types of work; this is the case of teachers, educators and other professional figures who work with children under age, because of the many stereotypes linking homosexuality with paedophilia ${ }^{[1]}$.

2.7 Transgender and transsexual persons experience even greater suffering due to what is described as transphobia: reactions of fear, disgust and discriminatory attitudes towards persons whose gender identity does not correspond in a socially accepted way to the sex allotted at birth. They have firstly to cope with the identification of transexuality and transgenderism as pathologies, a psychiatric problem to be treated (see paper by Whittle and Turner for details).

2.8 Moreover, the construction of citizenship is subordinated to a clear, socially approved relationship between sex and gender identity. In Italy a new name and a new legal identity may only be obtained when the operation of sexual re-attribution is completed, i.e. when the surgical transformation is irreversible and the adjustment between sex and gender is complete (Law 164 of 1982). In Spain, at present there is no specific law concerning transsexualism. Attending to the claims of transsexual associations, the Spanish Socialist Party, in power since March 2004, has drafted a new Ley de la Identidad de Género (Law for Gender Identity) which is now under review in the Spanish Parliament. The proposed law rules that documental reorientation should be obtained after two years of diagnosis and hormonal treatment, and that any psychologist or GP could be the diagnostician, thus trying to prevent giving the prerogative of diagnosis only to psychiatrists specialised in transsexualism (see the paper by Soley-Beltran for details).

2.9 They are equally the victims of a burdensome social exclusion: often rejected by their family of origin; 
simultaneously alienated by cultural, ethnic and religious communities; frequently excluded from support schemes (detoxification programmes; support groups; shelter centres for victims of sexual violence) which only assist persons whose gender identity conforms with biological sex. Moreover, although research studies are still insufficient to document the actual spread, preliminary studies indicate that the number of episodes of violence against them is very high. In a study carried out on the data from the Gender, Violence and Resource Access Survey, $50 \%$ of transgender subjects reported rape or aggressions by their partners. When explicitly asked, $31 \%$ of the sample identified with a survivor of domestic violence (Courvant and Cook-Daniels, 2000). Lastly, almost half of MtF (male to female) transsexuals prostitute or have prostituted themselves ${ }^{[2]}$, also because access to work and the maintenance of a working position may be very problematic: i.e. discriminatory attitudes, exclusion, mobbing, and even physical aggression ${ }^{[3]}$.

2.10 These problems were dealt with by the European Parliament in Resolution 1117 of 12 September 1989. In the text we read:

\section{The European Parliament}

considering that the procedure regarding change of sex by transsexuals has still not been provided for and regulated in all Member States of the Community or that the relative costs have not been assumed by insurance against illness;

considering that transsexuals are everywhere still discriminated against, excluded and at times even criminalised;

aware that the unemployment rate of transsexuals is $60-80 \%$ during the sex change phase; observing that transsexuality constitutes a psychological and medical problem, but also the problem of a society which is unable to deal with a change in roles conditioned by sex and fixed by cultural traditions;

\section{invites Member States}

1. to pass measures regulating the right of transsexuals to a change of sex, from the points of view of endocrinology, plastic surgery and aesthetics, and the relative procedures and to forbid their discrimination;

2. to take opportune measures for the costs of psychological, endocrinology, plastic surgery and aesthetic treatment to be reimbursed by insurance against illness;

3. to set up guidance centres for transsexuals who, due to their change in sexual nature, have blamelessly lost their jobs and/or homes;

4. to set up guidance advisory centres for transsexuals and to support their organisations financially;

5. to make information campaigns on transsexuals's problems, especially addressing social assistants, registry offices, police, military administration and prisons;

also invites

6. the Commission and Council to make it clear that community directives on the equality of men and women in the workplace also forbids discrimination against transsexuals;

7. the Commission, Council and Member States to make available identity documents which, on request, might indicate the transsexuality of the bearer during the period of adaptation of sexual features, and the aforesaid documents would be recognised throughout the Community;

8. the Council and Member States to recognise, within the framework of the harmonisation of asylum rights, persecution of transsexuality as a reason for granting these rights;

9. the Commission to make available, within the framework of its intervention programmes, funds for research into transsexuality and the spread of current medical knowledge on the subject;

10. the Commission to intervene with Member States to take special measures to facilitate job inclusion of transsexuals;

11. asks for the setting up of an office within the Commission, to which cases of discrimination may be reported;

12. charges its President to transmit the present Resolution to the Council, Commission, Governments and Parliaments of the Member States, as well as to the Council of Europe ${ }^{[4]}$.

2.11 But, of course, the transsexual condition does not necessarily coincide with social exclusion. There are a large number of successful women and men who have experienced complete transition while, in most cases, maintaining reserve regarding their past. The media also give coverage to transsexual people above all in cases when someone "well-known changes sex", and when they are the victims of discrimination, harassment and aggression. The stories essentially focus on their lives before the transition or on difficulties during transition, and rarely on after the sex change, Moreover, stories of failures, harassment and 
aggression attract a larger audience ${ }^{[5]}$. The lack of balance in the news coverage contributes to forming the opinion that gender changes necessarily have sad outcomes. Transsexualism and transgenderism make it possible to tell and understand how the processes of identity construction have changed in present-day or traditional societies, clearly showing how personal identity has become a polysemous construct. It is in fact an abandoning of the modern frame of sexuality in terms of a critical, creative re-crossing. It is not the renouncing of an identity, but the search for a fluid and, at the same time, authentic identity (see the papers by Monro; Hines).

2.12 Silence, having become deafening, has thus shrouded the scientific debate on the complexity of the gender-sex relation and sexual gender-desire. In many European countries reflection on these issues still has to be constructed. Only in the last few years has sociological research started to deal with homosexuality, bisexuality, transgenderism and transsexualism. This has prevented the adjustment and renewal of socialisation practices and reflection at institutional level, implicitly supporting the heterosexist model (see the papers by Soley-Beltran; Whittle and Turner).

2.13 Education to sexuality ${ }^{[6]}$, the plurality of sexual desire and the acceptance of "other" gender identities than the heterosexual model is still lacking in many European countries, both in the process of primary socialisation and in educational and school programmes. Recent empirical evidence shows that the question of sexuality continues to be a definitely taboo subject in families (e.g. Ruspini, 2003). The dialogue between parents and children on subjects such as love and sex is not an easy undertaking. Adults often feel more embarrassment than their children in dealing with issues which concern sexual relations or contraception. Modesty and the need to maintain their privacy drive girls and boys to seek the answers to their doubts and curiosities outside the family. People outside the family (often friends) in fact seem to be the main vehicles of information on sexuality, which is however often inexact, distorted or in any case insufficient ${ }^{[7]}$. Young people therefore are often unprepared and badly informed when they discover their sexuality, and find themselves having to handle the crucial knots of their life courses alone. For homosexual adolescents who, according to the World Health Organisation account for $5 \%$ of young people, the problem of handling sexual education becomes even more complex, and at times dramatic. The terms outlining the frames of a homosexual's adolescence are marked by their difference, but also by their rejection and fear of being discovered. The rigidity of male and female stereotypes, the lack of preparation in the school world, the social stigmatisation and lack of listeners are causes of a strong unease, and at times even of suicides or attempted suicides ${ }^{[8]}$.

2.14 The school system, furthermore, is not exempt from stereotypes linked to masculinity and femininity. If schooling seems to be based on a pedagogy which is defined as "neutral", in reality it distinguishes between "masculine" and "feminine" aptitudes and skills. In line with the models characterising the other agencies of socialisation, the institutional training system still today demands of young women demonstrations of "femininity" and compliancy, and offers young men a strong training, oriented to autonomy and the development of technical, logical and rational skills. The prevalent forms of learning in school educational and professional training systems are still essentially constructed to highlight traditional values and behaviours linked to feminine and masculine roles (see, among others, Presidenza del Consiglio dei Ministri, 1997; Boffo et al., 2003).

2.15 The family and the school system, perhaps the most important agencies of socialisation, do not therefore seem able to guarantee training suitable for the needs arising from changes in feminine and masculine identities. In the first case, it is often an "absent" institution and, when present, in strong continuity with the traditional conception of relations between women and men. In the second case, education to gender differences and sexual desire is still little developed.

\section{Leave to speak}

3.1 Today, this silence which is spreading in many directions, clashes with major trends in social change affecting the dimensions of gender identity and sexual desire: interweaving, crossings, passages, pluralisation and interchange.

3.2 Firstly, in the current historical phase marked by a strong tension between tradition and modernity, the boundaries of gender identity are being redrawn. While the strong divisions between "male" and "female" characterising past history still persist, these divisions must both tackle the intense transformations which have affected life courses, diversified the ways of forming a family, reduced the stability of nuclei and radically changed the forms of participation in the job market. These tendencies for change have, on the one hand, contributed to the increase of risks linked both to working to family life; on the other hand, they have favoured a drawing closer of male and female life courses both from the structural point of view (increase in women's employment and schooling; delayed entry into adult life; a shared lesser inclination for marriage and procreation; assumption by women of responsibilities which previously belonged exclusively 
to men, etc.), and in the way in which life courses are desired, planned, constructed, and redefined by the subjects themselves.

3.3 Women's biographies seem to be in a phase of great changes. The increase in women's education is in particular the factor which has most influenced the choices made by women. Educated girls get married later, decide to have a smaller number of children or not to have any at all, to subordinate family and affective life to their career, to commit themselves to active roles in the political and financial economic sphere, to no longer agree to experience the couple relationship according to the rules of inequality inherited from tradition. The latest generations of women are in particular well aware of the need for cultural training to achieve a satisfactory life. They achieve higher performances, their school careers proceed more smoothly, and they consider study more important; at the same time, they have high expectations regarding their entry in the labour market. Various research studies (see, for example, Schizzerotto, Bison and Zoppè, 1995; Bianco, 1997) show that, for girls, the lengthening of the training process brings much greater advantages than for boys: it facilitates finding work and enables them to obtain qualified jobs.

3.4 At the same time, women are affected by the growing tension generated by the encounter between tradition and modernity, i.e. by the difficult coexistence between social expectations (linked to gender roles); gender stereotypes; desire to procreate; desire and need to make a career also in non-traditional sectors (see the papers by Harris; Gill for details). Moreover, they are often still unprepared to deal with the growing male desire to share caring functions. In other words, women themselves act as a brake in the redistribution of caring tasks, delegating these functions to men. It is a field which has always been managed by women, imbued with "feminine knowledge". Women believe they are more able to take care of others, certainly more than any other person in the family and, in particular, than their partners.

3.5 On the one hand, while women are beginning to make their presence in society increasingly more substantial and visible (not without contradictions), on the other hand, there is a feeling that the process of reformulating male identity, although already taking place, is still in an initial phase and has not yet taken a precise direction. As Deriu states (1997), the processes of social change have inevitably clashed with a lack of male self-awareness: in observing themselves, understanding their own and other people's changes, and consequently adapting to the new relational needs along lines of gender and generation. Men essentially lack the suitable reflection which might lead to a real overcoming of gender prejudices.

3.6 Some men have accepted the challenges and invitations emerging in the process of the change in female identities, but often alongside regrets, doubts and perplexity; others have instead rejected them, reacting with fear and aggressiveness, tending towards an "attachment to models of stereotyped virility," reinforcing the model of masculinity which repudiates feminine characteristics and falls back on physical or verbal aggression, sexual harassment and homophobic attitudes. The different reactions vary according to the different characteristics of the men involved, in terms of age and generation, level of education, ethnic culture and social class. Indeed, men do not comprise a uniform group, nor is it possible to speak of a single male role. Masculinity is not always equivalent to power. Men lead many different types of lives and have many different interests. While men, masculinity and men's powers and practices were for a long time generally taken for granted ? gender was largely seen as a matter of and for women, men were generally seen as ungendered ? the taken-for-granted nature of men and masculinities is now changing. Men have become the subject of growing academic, policy and media debates.

3.7 Not only are men now increasingly recognised as gendered, but they, or rather some of them, are increasingly recognised as a gendered social problem to which welfare systems may or, for a variety of reasons, may not respond. This can apply in terms of violence, crime, drug and alcohol abuse, buying of sex, accidents, driving, and indeed the denial of such problems as sexual violence. Social and health statistics show that life in Western society demands a high price from men. Males are overrepresented among drug abusers and prison inmates. The life expectancy of men is shorter than women's. Boys display more problematic behaviour patterns in school than girls, and constitute a larger proportion of the pupils requiring remedial measures at primary school level. The drop-out rate for boys is considerably higher than for girls. The need for children to associate with men as well as women in day-care institutions, schools and in family life has been well documented. There is general concern from a gender-equality perspective that day-care institutions and schools remain a female-dominated environment. All these issues are relevant to the development of new ways of being a man and will play a decisive part in the development of a culture of gender equality (see the paper by The WASS collective).

3.8 One of the areas in which male gender roles have changed the most involves men's role as fathers. Fathers neither have nor operate a single model of fatherhood: research indicates that fatherhood leads men to make the most explicit break with traditional forms of masculinity. Today, men and fathers are expected to be accessible and nurturing as well as economically supportive for their families and children. Indeed, studies on the impact of father involvement in childcare on later child outcomes confirm the importance of early paternal investment both in caring and in improving opportunities for women. However, 
fathers' involvement in caring tasks and housework seems twofold. On the one hand, following some evidence, men in general are spending more and more time (changing diapers/nappies, playing) with their children, albeit still at a lower level than mothers. On the other hand, father's involvement in housework remains low, contributing to women's feelings of overload, particularly for full time working mothers. Fathers are also unlikely to take parental leave, even when it is offered. And it is true that most non custodial fathers spend very little time with their children.

3.9 It is also true that the desire of fathers to be more involved in the first year is increasing. This tendency is also twofold. On the one hand, the fathers' rights movement is characterised by the presence of men who feel pushed out, denied ties with their children, leaving them estranged and angry. The underbelly of this is anger toward women. On the other hand, while more and more men are eager to spend more time at home, the stigma remains. While much of society is aware of the increasing generational gap, the role reversal is still a foreign concept. At-home dads encounter ignorant questions at the park, in the supermarket or while simply walking their child down the street: Are you taking the day off work today? What is your real job? ${ }^{[9]}$

3.10 Homosexual fathers face a more difficult challenge. First, family forms outside heterosexual married couples do not get similar, positive support from social policy systems. Second, for some authors, "responsible fathering is most likely to occur within the context of heterosexual marriage". Finally, there is little discussion of the experiences of fathers and the constraints they face, and little reference to available research: what are the social and cultural obstacles which prevent men from carrying out their fathering role? What keeps them from participating in child care as much as they might?

3.11 A new phenomenon is also emerging at cultural and symbolic level: the movement for fathers' rights. While men generally are starting to claim greater participation in the upbringing of their children, unmarried and divorced fathers claim the right to regular time spent with their children entrusted to the mother. The various associations of separated fathers have sprung up to fight the current restrictive legislation preventing them from carrying out their educational role in the separation. The main demand is for joint custody as a standard, based on parents' equal rights and duties.

3.12 All these contradictory factors bring to light the delicate problem of the search for a new equilibrium between the sexes and the need for new forms of relationship between them, a compulsory step in the radical transition a self-redefinition of the "new" women and "new" men (see the paper by The WASS Collective). Indeed, the processes of social change often fit into cultural contexts which are still bound by traditional values. While gender identities, family models and participation in the job market are rapidly changing, the symbolic references governing the relations between men and women are slow to change. Social change has generated disorientation in gender relations. We may speak, for example, of women's growing demand for reciprocity and equality (also at sexual level) with men or the increasingly substantial female competition in traditionally "male" sectors (see the papers by Harris; Gill). Or again, the questioning of the traditional model of the organisation of family life and the arising of new directions in the development of cohabitation: single-parent, reconstructed and homosexual families (see the paper by Shipman and Smart; Reynolds).

3.13 For these reasons, sexual polarisation - a particularly intense focus in the thinking and daily practices of the modern Western world - is today undergoing a problematic revision on which it is impossible not to reflect. The rigid conception of bi-polar and dualistic gender (female versus male and vice versa) - based on an idea of dual sexuality and tending towards the separation of the sexes, i.e. reconstructing motivations for an encounter or reasons for attraction on their otherness and diversity and distance - is seen as increasingly "narrow", because there is no perfect correspondence between sex and gender, between sexual identity and sexual practice (Lorber, 1994). In other words, there are different levels in the accepted meaning and conformity to social expectations within one's gender identity: a space "between the genders", a "post-modern sexuality" (Baudrillard, 1979, pp. 13-15) which includes wings, transformations, nomadisms, an incessant metamorphosis of identity, a multiplicity of ways of being and creatively expressing the combination between gender and sexual desire. The process of gender acquisition may in fact turn into experiences and behaviours which are fully, little or in no way concordant with biological sex and with social expectations co-related to it (see the papers by Monro; Hines).

3.14 Gender research must take into account and explore all these novelties, without merely documenting already known phenomena. A broadening in various directions therefore becomes necessary:

- that of the socialisation processes to gender identity and the tension between these processes and on-going trends in social change. While, on the one hand, these trends seem to lead towards a flattening of the gender differences and to a convergence of life courses, on the other hand, socialisation agencies are still unable to guarantee adequate training for the needs arising from the changes in female and male identities. It is increasingly necessary to understand and work through tensions and changes which have affected the social organisation of the gender relation to begin the 
deconstruction of a discriminatory socialisation which affects both girls - trained to undertake caring tasks, brought up to cover secondary social roles and socialised to renouncement - but also male children and boys, in supporting the rigidity characterising the dominant male model, unable to adapt to the on-going processes of social changes;

- secondly, the relation between the redefinition process of female and male identities (and hence of gender relations) and the approach to forming a family: the new forms of motherhood and fatherhood; the new forms of cohabitation. What meanings do these choices take on for the subjects (women and men) who decide to put them into practice?

- thirdly, a greater development of knowledge in the field of masculinity and male pluralities. While the changes in the roles of women have been widely debated in the last ten years (both in women's thinking and in that of men), those relating to men have been much less discussed. Does masculinity continue to be perceived (by men and women alike) as essentially linked to the rights to power and dominion? Or are other models, more egalitarian and oriented to sharing, making their appearance? The most important conclusion in the research conducted in this field asserts that there are different forms of masculinity and that the dominant, violent, homophobic form is not the only one or the most prevalent;

- lastly, the plurality of sexual directions: the growing social visibility of transgender identities, sexual "nomadism".

\section{Educating to diversity}

4.1 The road to "breaking the silence" is still long. Training to a culture in which gender is the expression and rebalancing of the historical imbalance between the male and female genders needs many closely interconnected elements: from the removal of gender stereotypes (a process which must involve all the agencies of socialisation); to the need to impose new, more consonant training processes for the new generations (we may think, for example, of the importance of a new structuring of school texts) including training for parental functions and care; the strengthening of sexual education and the plurality of gender identities in the training system.

4.2 Within this process, we may mention the pressing need to prepare the new generations of men to an equal distribution of family tasks, care functions, a different, more reflective form of fatherhood which is capable of affective, emotional contact with their children.

4.3 There are various reasons for this. First and foremost, to attempt to limit and deconstruct certain gender stereotypes hindering the development of a richer, more flexible and egalitarian masculinity oriented to sharing. We may think of the following statements: "Men are in crisis today" or "Men aren't like they used to be", or again "Men have become feminised". Or, lastly in terms of "mammo" (instead of "mamma"), "effeminate male", "soft male". Speaking of a "feminisation" of contemporary men (and, at the same time, of a "masculinisation" process of women) seems somewhat facile. It has also favoured, and not only within male thinking, the spread of a social alarm concerning the dangers of the "feminisation" of modern men, which betrays a widespread anxiety regarding a frightening and feared feminine advance (Bellassai, 2002, pp. 198-199).

4.4 In order to set up off processes of reflection (and prevention) on the dark sides of masculinity, we may then speak of gender violence; of homophobia; of the limits imposed by stereotyped masculinity maleness towards women, children, male genealogies, "other" forms of masculinity, of men's difficult, often inexistent dialogue with their bodies. Many men continue to use (physical, psychological, sexual and economic) violence to maintain or strengthen their power or to block a regression of this power. We may think of many episodes of gang rape (often organised by young men against young women); of the increasingly frequent murders of former wives, partners, and often children; of the acts of violence against homosexual or foreign persons (men and women). Gender violence, which presupposes a body used as a weapon, in other words constitutes one of the possible reactions to the evident changes in women's life courses and of their own masculinity. It is an expression of rage, impotence, confusion and disorientation towards what can no longer be understood and controlled.

4.5 Furthermore, to favour the dialogue between women and men, especially between the younger generations who, more than previous ones, will have to deal with the complex trends in social change. As we have already discussed, the delicate problem which emerges today is linked to the need to find a new equilibrium between the genders in the light of the radical transitions to a self-re-definition of the "new" women and "new" men; changed lifestyles, a different use of time and space, new focuses entrusted to personal and professional investment.

4.6 Lastly, the need is emerging to promote a gender equality - seen as that particular kind of equality in rights, access to resources, public services and decision-making processes, respecting gender difference with the joint involvement of women and men. The re-composition, through dialogue and mutual knowledge, 
of the historical rupture between male and female may bring with it equally positive effects. Concerning women, this means deconstructing the processes of financial dependence on male income; increasing their share in the labour market; re-balancing time schedules to facilitate the conciliation between life and work demands and, at the same time, improving their health. Regarding men, the positive effects include the possibility of re-appropriating a part of their gender identity, historically denied: we mean the functions of nursing, care and socialisation.

4.7 Among the on-going projects, we may mention, for example, an interesting experience in the publishing field. This is the Polite Project (acronym: Pari Opportunità nei libri di testo - Equal Opportunities in Textbooks), set up in the years 1998-1999, and which several publishing houses have joined. Polite is a European self-regulation project for textbook publishing. It was set up to promote cultural, didactic and publishing considerations to rethink textbooks to ensure that those women and men who have led the way in culture, history, politics and science are represented in textbooks with no discrimination based on sex. In more general terms, Polite intends to ensure that women and men are equally represented in school books, so that the contemporary world can be analysed and knowledge for the generations to come can be built up with greater awareness of gender identity, forming new and different relationships between men and women. It is at school that recognition of differences can have real and practical possibilities, thus becoming the personal heritage of all young people in an equal opportunities perspective ${ }^{[10]}$.

4.8 The first edition of Polite (1998/99) gave rise to the following:

- a European study into how equal opportunities issues are taken into account in textbooks (downloadable from the website);

- a self-regulation code incorporating the gender perspective to encourage the production of textbooks which represent women and men in an equal manner and which help students of both sexes build up their own identity;

- seminars, workshops and a European conference for discussion and awareness raising.

4.9 Polite II is the continuation of the project, which is divided into two one-year editions (1999/2000 and 2000/2001). Polite II intends to ensure application of the knowledge acquired. It is thus necessary to provide real tools to effect a change which emanates from publishing and from schools to raise awareness of equal opportunities issues throughout society. Results achieved in the 1999-2000 edition include:

- a census of teaching instruments and pedagogical materials on textbooks, drafted in a European context and inspired by the principles of equal opportunities (downloadable from the website);

- a Vademecum for textbook authors, to flank the Self-regulation Code as a means of ensuring works that carefully consider equal opportunities;

- experimentation of educational tools and strategies in Italian schools to raise awareness about gender issues;

- a review module with special tools (including the Polite Movie educational video) for teachers, to assist them in the use of innovative texts with a gender perspective;

- raising awareness among experts and the broader public through seminars, workshops, and conferences.

4.10 The project is working on the following actions during the current year, 2000-2001:

- a second Vademecum for textbook authors, bringing together the disciplines dealt with in the previous edition;

- new features and activities for the web site;

- continuation of the experiments carried out in Italian schools on educational strategies and tools with a gender perspective;

- comparison between the teaching experiences in the field of equal opportunities in Italy, Spain and Portugal;

- a professional retraining seminar on gender issues and the application of Polite instruments, targeting staff and editors of textbook publishing companies;

- a final conference open to the public.

4.11 Another worthwhile example is the "Triangle-Transfer of Information to Combat Discrimination Against Gays and Lesbians in Europe" a transnational action with the aim of exchanging information and good practice within the framework of the "Community Action Programme to Combat Discrimination" of the EU. Triangle is a network of co-operation partners within Europe who agree on a string of concrete goals in the sector of information as well as educational work in order to reduce discrimination. The transnational network includes organisations and groups whose actions address the following two grounds of discrimination: sexual orientation and ethnic origin in order to ensure a creative and holistic exchange of ideas and approaches. This project includes a manual whose main principle is to deal with the theme of 
discrimination based on sexual orientation in a multi-cultural society. The manual addresses teachers, psycho-social operators, students and young people. It condenses the know-how and experiences of many specialists in the field and sets out to be a useful tool to enact a more in-depth understanding of the fundamental dimensions implied in the fear of the "other"[11].

4.12 Social and public policy could play some role in promoting the necessary cultural change that can support a more active participation of men and fathers in the development of gender equality. The higher level of involvement by fathers in caring tasks should be promoted in a way that is sensitive to the needs of mothers and children. We could mention the importance of flexibility for fathers to allow mothers a real choice in returning to work. Such initiatives might include funding and promoting research and debate around this issue. Moreover, these projects should not treat men as merely the subject of research, but should try to develop a partnership approach between men and women in developing the research, planning and participating in seminars and workshops as well as developing subsequent policies for changing behaviour. We could mention the thematic network "The European Research Network on Men in Europe: The Social Problem and Societal Problematisation of Men and Masculinities". This brings together the work of the European Research Network on Men in Europe that has been operating since March 2000, within the EU Framework 5. The overall aim of the Thematic Network is to develop empirical, theoretical and policy outcomes on the gendering of men and masculinities in Europe. The central focus of the Research Network's effort is the investigation of the social problem and societal problematisation of men and masculinities. The reference to "social problem" refers to both the problems created by men, and the problems experienced by men. The notion of societal problematisation refers to the various ways in which the 'topic' of men and masculinities has become and is becoming noticed and problematised in society - in the media, in politics, in policy debates, and so on. This focus is set within a general problematic: that changing and improving gender relations and reducing gender inequality involves changing men as well as changing the position of women. The report also provides information on the other Network outputs, including the European Data Base and Documentation Centre on Men's Practices ${ }^{[12]}$ and relevant publications of Network members, arising from the Network's activities.

4.13 There are also good examples of men's involvement in building a culture of peace. They include both community activism and governmental programs (UNESCO, 1997):

- The Canadian "White Ribbon" campaign, a broad program of community involvement to reduce men's violence against women, now spread to a number of other countries.

- The Nordic countries' "fathers' quota" (or "Dad's Month") of parental leave, and experience in recruiting significant numbers of men to work in child care centres.

- The South African "Truth and Reconciliation Commission" and community actions such as the "We Shall Remember Them" campaign about road deaths.

- Anti-sexist and anti-racist men's groups in a wide range of countries from Russia to Australia, such as the "National Organization of Men Against Sexism" in the United States.

- Efforts to change occupational cultures of violence by in-service programs for police, in countries such as El Salvador and the Philippines.

- Development of gender-specific programs for boys in Australian schools, addressing issues from literacy to human relations and violence, allowing boys to examine issues about masculinity.

4.14 We may lastly refer to the many collective experiences - there is a very long list of men's rights organisations and the men's and fathers' organisations - which fit into a male network of reflection on the dominant models of maleness: men who choose to speak up on issues regarding violence, on relations between the sexes, on cultures and languages generated by patriarchalism starting from their identity and their sexual experience. These working groups have brought about a critical appraisal of the historical experience and identity models of masculinity, within which the confrontation with women and the dialogue with the thinking and practice of feminism has been a decisive factor (Ciccone, 2005).

\section{This special section}

5.1 This collection of papers on the theme of gender transformation is, then, a call for a range of discussions about issues and problematics which are crucially important for the discipline of sociology, but also of central importance for how we understand processes of social change.

5.2 This special section sets out to contribute to the culture of diversity, opening up new paths for reflection on tensions and challenges linked to the changes in gender identities. The intention is to discuss, in the light of new contributions for both qualitative and quantitative reflection and research, certain directions in the major transformations in the perceptions and self-perceptions of women and men and in gender relations, also in the light of the plurality of sexual orientations.

5.3 The directions taken by women and men writers are multiple and strongly inter-connected: 
transformations in gender identity; changes in the relations between women and men (in particular among the younger generations); the relation between research, the school system and gender; the plurality of family models; homosexuality; transgenderism; transsexuality.

5.4 All the papers witness that gender is a rich, complex relational and historical dimension. Only the examination of the mutual influence of women and men, of their bonds and contrasts, may enable us to understand what the "women's" and "men's condition" is. Masculinity and femininity are a function of (present, past and future) reciprocal perception and interaction. Being a woman and being a man are both the product of a historical process which has traversed different cultures and societies, within which masculine and feminine have been differently defined, creating specific collective and individual identities. Gender relations also change constantly, as the social norms regulating specific behaviours vary between cultures.

5.5 The collection of writings lastly bears witness to the importance of reflection on the plurality of sexual orientations and hence of female and male models. The process of gender identity acquisition may turn into experiences and behaviours fully, slightly or in no way concordant with biological sex and with the social expectations related to it. This highlights the tension between the terms of sex, gender and desire, on which the normalisation of heterosexuality is based.

5.6 To sum up, the aim of this Special Section is to contribute to conveying masculine and feminine models which are as dynamic, realistic and free of stereotypes and prejudices as possible, but which may at the same time reflect the complexity, richness and creativity characterising gender identity and the relations between sex and gender. A more balanced, innovative vision, more attentive to the on-going changes, seems fundamental to resolve many of the questions which today affect relations between genders and generations.

\section{Notes}

${ }^{1}$ A research study on the sexual exploitation of minors in tourism (Scarpati, 2005) - based on the processing of data obtained directly from surveys carried out by the police forces in some countries in Europe (including Italy), North America and Asia, as well as from the personal archives of some of the collaborators, such as criminologists, lawyers, psychologists - shows that in the cases examined, $93 \%$ of clients are male, $20 \%$ of them state they are solely homosexual, while $65 \%$ state they are solely heterosexual. The percentage describing themselves as bi-sexual is $15 \%$.

${ }^{2} \mathrm{MtF}$ transsexuals tend to have feminine features according to several clichés, often seen in various traditional forms of the femme fatale, vamp or pin-up, or in any case of a sexually seductive woman. The femininity of transsexuals is thus at times caricatural, other times simply exaggerated, but this also meets their need to emphasise and communicate their new identity, to distance themselves from their previous one, and rub out any trace of it. Apart from this, however, something erotically determining persists, to the point that they are subject to a growing and specific concupiscence, a particular desire, able to fuel and support their prostitution (http://www.psicologiaonline.it/Transessualità.html). The transsexual woman is often only recognised as a woman if she is "more womanly than all women", i.e. if she is a hyper-woman. In this way the relation with one's body becomes more complex, and everyday citizenship constructs it referring to an ideal of perfection which demands continual interventions on one's corporality. These bodies are thus also subjugated to a social order dominated by male gaze, desire and culture.

${ }^{3}$ Saraceno, 2003; <http://freewe.supereva.com/aitfirenze/Approfondimento.html?p>

4 <http://www.crisalide-azionetrans.it/EUrisoluzione1117.html>

5 <http://ai.eecs.umich.edu/people/conway/TSsuccesses/TSsuccesses-Italian.html>

${ }^{6}$ By sexuality we mean not only the biological datum (being sexed and having sexual relations), but an integral aspect of individual identity which "each of us 'has' and cultivates, rather than a natural condition which the individual accepts as a fact. In some way, and this must still be researched, sexuality functions as a malleable trait of being, a primary nexus between body, identity of self and social rules" (Giddens, 1992).

${ }^{7} \mathrm{~A}$ sexual educational project conducted in Italy, with the involvement of families and teachers, by the Institute "O. Romero" in Rivoli, Turin (Giommi and Perrotta, 1998) shows that parents, despite declaring themselves in favour of sexual education in schools, expressed discomfort at being interviewed $(41 \%)$ and an even lower number $(23 \%)$ answered questions relating to the discussion of sexual problems with their 
children. $50 \%$ do not know of the existence of family planning clinics and advisory centres for adolescents, $56 \%$ occasionally buy books and magazines dealing with sexual subjects from the medical point of view. In short, interest in sexual education is limited to subjects which help to protect their children from unwanted pregnancies and sexually transmitted diseases.

$8<$ http://www.leculture.net/cioffari.htm>; <http://www.fsw.ucalgary.ca/ramsay/homosexualitysuicide/Conference/>

$9<$ http://www.slowlane.com/articles/modern_day_dad.html>

$10<$ http://www.zadig.it/news2001/sci/0508-1.htm>

$11<$ http://www.arcigaymilano.org/crono/pdf/tria/it-teoria.pdf>; <http://.triangle-info.de/>

$12<$ http://www.cromenet.org >

\section{References}

BAUDRILLARD J. (1979), De la Séduction, Galilée, Paris.

BELLASSAI S. (2002), Maschilità e mutamento nell'Italia contemporanea, in C. Leccardi (ed.), Tra i generi. Rileggendo le differenze di genere, di generazione, di orientamento sessuale, Guerini, Milano, pp. 194-224.

BIANCO M.L. (1997), Donne al lavoro. Cinque itinerari fra le diseguaglianze di genere, Scriptorium, Torino.

BOFFO S., Gagliardi F., La Mendola S. (2003), La luce che non c'è. Indicatori di genere in campo formativo, in F. Bimbi (ed.), Differenze e diseguaglianze. Prospettive per gli studi di genere in Italia , II Mulino, Bologna, pp. 189-214.

CICCONE S. (2005), Oltre la misera del maschile. Un percorso di ricerca e liberazione, in E. Ruspini (ed.) Donne e uomini che cambiano. Relazioni di genere, identità sessuali e mutamento sociale, Guerini, Milano, pp. 167-180.

COURVANT D., Cook-Daniels L. (2000), Transgender and Intersex Survivors of Domestic Violence: Defining Terms, Barriers and Responsibilities.

GIDDENS A. (1992), The Transformation of Intimacy. Sexuality, Love and Erotism in Modern Societies , Cambridge, Polity Press.

GIOMMI R., Perrotta M. (1998), Educazione sessuale come prevenzione. Nuovi modelli per la famiglia, la scuola, i servizi, Edizioni Del Cerro, Pisa.

LORBER J. (1994), Paradoxes of Gender, Yale University Press, New Haven.

PARSONS T. (1954), Essays in Sociological Theory, The Free Press, New York.

PRESIDENZA DEL CONSIGLIO DEI MINISTRI - Dipartimento Affari Sociali (1997), Un volto o una maschera? I percorsi di costruzione dell'identità - 1997 Report on the Condition of Childhood and Adolescence, Istituto degli Innocenti, Florence, <http://www.minori.it/archivi/pubbli/rapporti/97/indice.html>

RUSPINI E. (ed.) (2003), Progetto Identità di genere, Research report, Università degli Studi di MilanoBicocca, Dipartimento di Sociologia e Ricerca Sociale, October 2003.

SARACENO C. (ed.) (2003), Diversi da chi? Gay, lesbiche, transessuali in un'area metropolitana, Guerini, Milano.

SCARPATI M. (2005), "II Turismo insostenibile: lo sfruttamento sessuale dei minori", in E. dell'Agnese, E. Ruspini (eds.) Turismo al maschile, turismo al femminile. L'esperienza del viaggio, il mercato del lavoro, il turismo sessuale, Cedam, Padova, pp. 311-362.

SCHIZZEROTTO A., Bison I., Zoppé A. (1995), Disparità di genere nella partecipazione al mondo del lavoro e nella durata delle carriere, Polis, April.

UNESCO (1997), Male Roles and Masculinities in the Perspective of a Culture of Peace, Conference Proceedings, Expert Group Meeeting, Oslo, 24-28 settembre 1997,

<http://www.unesco.org/cpp/uk/projects/oslotoc.htm> 
SCOTT W.J. (1999), Gender and the Politics of History , Columbia University Press, New York (revised edition). 